\section{International Scientific Journal Theoretical \& Applied Science}

\author{
p-ISSN: 2308-4944 (print) e-ISSN: 2409-0085 (online) \\ Year: $2015 \quad$ Issue: $01 \quad$ Volume: 21 \\ Published: $30.01 .2015 \quad$ http://www.T-Science.org
}

Tatyana V. Nikulina

Professor of the Ural state pedagogical University, Ural state pedagogical University, director of the center of distance technologies and education quality, candidate of pedagogical Sciences. Russia tatyana-nikulina@yandex.ru

SECTION 21. Pedagogy. Psychology. Innovations in the field of education.

\title{
E-AND DISTANCE LEARNING: THE NATURE AND QUALITY
}

Abstract: The article discusses the essential characteristics of electronic and distance learning, as well as a description of the process of implementation of educational programs with the use of electronic and distance forms of education, criteria and indicators of quality.

Key words: e-learning, distance learning, learning process, educational resources, quality, quality management system, process, outcomes.

Language: Russian

Citation: Nikulina TV (2015) E-AND DISTANCE LEARNING: THE NATURE AND QUALITY. ISJ Theoretical \& Applied Science 01 (21): 134-138. doi: http://dx.doi.org/10.15863/TAS.2015.01.21.23

\section{ЭЛЕКТРОННОЕ И ДИСТАНЦИОННОЕ ОБУЧЕНИЕ: СУЩНОСТЬ И КАЧЕСТВО}

Аннотация: B статье рассматриваются сущностные характеристики электронного и дистанциионного обучения, а также описание процесса реализации образовательных программ с применением электронной и дистанционной форм получения образования, критерии и показатели качества прочесса.

Ключевые слова: электронное обучение, дистанционное обучение, учебный прочесс, образовательнье ресурсы, качество, система менеджмента качества, процесс, образовательные результаты.

Инновационные формы получения образования основаны на информационно коммуникационных технологиях обучения, которые являются одним из компонентов системы непрерывного образования. Востребованность организации дистанционной и электронной форм обучения в системе высшего образования возрастает с каждым годом в связи с возросшими потребностями потребителей образовательных услуг. Проблемные ситуации, связанные с закрытием филиалов и представительств университетов; студентами, проживающими в депрессивных и территориально отдаленных территориях; обучением детей - инвалидов; ускоренной формой обучения (погашение задолженностей, разницы в учебных планах); болезнью студентов; получением дополнительного образования и другое, ориентируют образовательные организации на поиск новых подходов к организации учебного процесса. В век информатизации системы образования целесообразно искать пути интеграции различных форм обучения и форм получения

образования, что допустимо в соответствии с Федеральным Законом «Об образовании».

Электронное и дистанционное обучение ориентировано на создание образовательной среды без границ, обеспечивающей интерактивную коммуникацию между педагогом и студентом [6, с.5]. Возможность получения образования посредством инновационных форм с применением образовательных ресурсов: электронных библиотек, научных центров с удаленным доступом к открытым образовательным ресурсам предоставляют возможность потребителям выстраивать индивидуальные траектории обучения, развивать способности и личностные качества, осваивать профессиональные компетенции в различных сферах деятельности, обучаться в течение всей жизни.

Электронное и дистанционное обучение является самостоятельной, инновационной формой получения образования [6, с. 4]. Ключевым понятием данных форм получения образования является учебный процесс, организация которого является актуальной 
проблемой образовательных организаций в связи с тем, что большинство педагогов отождествляют дистанционное и электронное обучение. В соответствии с Законом РФ «Об образовании» электронное обучение реализуется с применением содержащейся информации на сервере дистанционного обучения, дистанционное при опосредованном взаимодействии педагога и обучающихся [1,c.58]. Другими словами, электронное обучение (ЭО) организация образовательной деятельности с применением содержащейся в базах данных и используемой при реализации образовательных программ информации и обеспечивающих ее обработку информационных технологий, технологических средств, а также информационно - телекоммуникационных сетей, обеспечивающих передачу по линиям связи указанной информации, взаимодействие обучающихся и педагогических работников. Дистанционное обучение (ДО) - опосредованное (на расстоянии) взаимодействие обучающихся и педагогических работников с применением информационно-телекоммуникационных сетей [5, с.4]. Каждому участнику учебного процесса необходимо понимать, что дистанционная форма обучения не должна отождествляться с самообразованием, потому что самообразование это самоорганизация человека, направленная на личностное развитие [3, с. 4]. Учебный процесс является составной частью целостного педагогического процесса, направленной на достижение целей обучения. Роль педагога независимо от формы получения образования и формы обучения важная, т.к. он осуществляет контроль учебного процесса с целью обеспечения образовательного результата направленного на развитие личности. Потенциал образовательной организации ориентирован на обеспечение качества образования за счет создания конкретных ресурсов обучения, гарантирующих достижение образовательных результатов [4, с.7]. Образовательные результаты отвечают требованиям федерального государственного стандарта и потребителей. К образовательным результатам относится: освоение знаний и умений, формирование компетенций, развитие информационной культуры, развитие познавательных интересов. Оценка образовательных результатов осуществляется такими индикаторами как мобильность, операциональность выпускников, способность овладевать различными формами получения знаний и умений применять их в профессиональных, жизненных ситуациях [7, с. 1]. Новиков А.М. отмечает, что необходимо обеспечить разнообразие форм образования для свободного продвижения человека в образовательном пространстве [2, с.2]. Интеграция форм обучения и получения образования позволит изменить идеологию содержания образования, построения образовательного процесса посредством новых организационных форм учебной деятельности, взаимодействия педагога и обучаемых, ориентированных на востребованные обществом образовательные результаты. Достигнутыми образовательными результатами определяется качество обучения. Оценка результатов и качества обучения определяются степенью освоения целями образовательной программы. Выявление уровня сформированности компетенций, изменений в личностном развитии и недостатков учебного процесса, включая поиск механизмов его улучшения, позволяет система оценки качества обучения. Качество обучения определяется соответствием образовательных результатов, направленных на индивидуальные потребности и потребности общества [8, с.24]. Качество обучения основано на информационных образовательных ресурсах, доступных потребителям образовательных услуг, предусматривающее их умение работать с информацией. Однако, возникает проблема неготовности педагогов и работников образовательных организаций к овладению информационными технологиями для организации учебного процесса с применением электронного и дистанционного обучения [10, c.197]. Этапы проектирования учебного процесса, методического и технологического его обеспечения являются актуальными в образовательных организациях. Выстроенная в организациях система менеджмента качества не предусматривает полномочия и ответственность каждого участника учебного процесса, что обуславливает хаотический характер обучения и несоответствие образовательных результатов целям обучения. Возникает вопрос: каковы требования к реализации образовательных программ с применением различных форм обучения? Каков регламент взаимодействия участников образовательного пространства?

Эффективным инструментом обеспечения целей в области качества обучения, ожиданий потребителей является система менеджмента качества [9, с.82]. Система менеджмента качества ориентирована на выявление ошибок учебного процесса и незамедлительное их устранение. Причины ошибок всегда являются неправильные действия, которые необходимо формализовать для соответствия целей обучения и полученных образовательных результатов. Деятельность по установлению структуры и механизма ее управления определяется документированием системы менеджмента качества. Целью 
документирования является создание нормативной и организационно-методической основы построения и функционирования системы менеджмента качества, соответствующей требованиям стандартов ISO. Система менеджмента качества включает в себя следующие элементы: процессы, документы и ресурсы, включая образовательную организацию. Процесс - совокупность элементов, ориентированных на «входы» и «выходы». Безусловно, «входами» процесса являются выходы других, взаимосвязанных процессов. Процедура - правильный способ осуществления процесса, алгоритм действий. Процедура основана на документах, направленных на правильное выполнение процесса. Ресурсы обеспечивают качество образовательных услуг. Каждый элемент системы менеджмента качества взаимосвязан и направлен на достижение поставленных целей. Другими словами, для того, чтобы получить образовательный результат необходимо описать действия каждого участника учебного процесса и контролировать их выполнение для мобильной их корректировки.

Эффективное функционирование системы менеджмента качества зависит от соответствия процессов разработанным нормативным документам. Характеристиками эффективного функционирования системы менеджмента качества в образовательной организации являются: управляемость, прозрачность и развитие. Рассмотрим подробнее содержательную составляющую процесса «Реализация образовательных программ с применением электронных и дистанционных форм обучения» в соответствии с требованиями стандарта ISO. Каждый процесс имеет следующую структуру: цель, владельца, входы выходы, ресурсы, систему контроля, показатели и критерии оценки процесса. Целью процесса является повышение доступности образования, максимальное удовлетворение спроса на образовательные услуги, повышение качества подготовки обучающихся за счет внедрения новых технологий и средств обучения. Потребителями и заинтересованными сторонами процесса являются: студенты и слушатели (внешние потребители), структурные подразделения образовательной организации, профессорско-преподавательский состав, сотрудники (внутренние потребители). Заинтересованные стороны: государство, работодатели. Входом в процесс являются:

- требования к реализации основных образовательных программ;

- требования потребителей к доступности обучения и методическому обеспечению, а так же выходы процессов «Проектирование и разработка образовательных программ», «Реализация основных образовательных программ», «Взаимодействие с потребителями». Выходом из процесса являются:

- результаты обучения;

-удовлетворенные требования потребителей в аспекте доступности обучения;

- повышение эффективности процесса обучения;

- повышение технологичности процесса обучения.

Вход и выход процесса реализации образовательных программ с применением различных форм получения образования отличен только управлением и обеспечением процесса. Управление процессом «Реализация образовательных программ с применением электронных и дистанционных форм обучения» осуществляется через следующие процессы и действия:

- планирование процесса;

- анализ процесса и его результатов;

- корректирующие и предупреждающие действия;

- управление документацией в рамках процесса;

- управление записями в рамках процесса.

Обеспечение процесса:

- библиотечное и информационное обеспечение;

- управление информационной и образовательной средой;

управление инфраструктурой и производственной средой.

Основным условием реализации образовательных программ с применением электронных и дистанционных форм обучения является доступ обучающихся к электронной информационно-образовательной среде, которая представляет собой совокупность информационных и коммуникационных технологий, соответствующих технологических средств, достаточных для организации опосредованного (на расстоянии) взаимодействия студентов и слушателей с педагогическими работниками, учебно-вспомогательным, административноуправленческим персоналом, а также между собой. Наполнение электронной информационнообразовательной среды во многом зависит от педагога, который размещает учебно методические комплексы в систему дистанционного обучения.

Входы процесса:

- списки групп (выход процессов «Прием абитуриентов» и «Управление записями»);

- требования к содержанию и оформлению электронного учебно - методического комплекса (ЭУМК), выпускной квалификационной работы 
(курсовое проектирование) (выход процесса «Управлении документацией»);

- требования к содержанию и оформлению документов по практике (выход процесса «Организация и проведение всех видов практик»);

- график учебного процесса (выход процесса «Реализация основной образовательной программы»);

- разработка ЭУМК (вход процесса «Реализация основных образовательных программ (ООП)»);

- техническое и информационное оснащений учебного процесса (выход процесса «Управление информационной средой»);

- информация о работе в системе дистанционного обучения (СДО);

- информация об услугах информационноинтеллектуального центра «Научная библиотека университета»;

- подготовка аудиторного фонда для он-лайн занятий;

- проведение он-лайн занятий в соответствии с утвержденным расписанием;

- учет выполненных заданий в СДО (выход процесса «Управление самостоятельной работой обучающихся»);

- прохождение практики (вход процесса «Организация и проведение всех видов практик»);

- отчет студентов об итогах прохождения практики;

- рекомендации по совершенствованию практики;

- информация о претензиях или неудовлетворенности качеством обучения (выход процесса «Взаимодействие с потребителями»);

- рекомендации по отчислению студента, связанные с невозможностью дальнейшего обучения (выход процесса «Управление записями»);

- рекомендации по совершенствованию учебного процесса с применением ЭО и ДО (выход процесса "Улучшение процессов").

Выходы процесса:

- учет контингента;

- организационно-нормативные документы;

- рабочий учебный план (выход процесса «Реализация ООП»);

- размещение ЭУМК и организационнонормативных документов в СДО;

- выдача логинов и паролей студентов доступа в СДО (выход процесса «Управление информационной средой»);

- выдача логинов и паролей обучающихся для работы с электронными ресурсами библиотеки (выход процесса «Библиотечное и информационное обслуживание»);
- расписание занятий, включая график консультаций;

- учет посещаемости он-лайн занятий обучающимися;

- заполнение электронного журнала успеваемости (процесс «Контроль знаний студентов»);

- отчёт о выполнении учебной программы (выход процессов «Реализация ООП»);

мониторинг удовлетворенности потребителей образовательных услуг (вход процесса «Взаимодействие с потребителями»);

- отчисление обучающихся, в связи с невыполнением учебного плана (выход процесса «Управление несоответствиями»); ГИА.

- обучающийся, подготовленный к сдаче

Критерии качества процесса: качество содержания образования (показатели, например, база учебных материалов в СДО: соответствие содержания курса утвержденной учебной программе; соответствие объема материала установленным нормам и т.д.. Техническое обеспечение: достаточность в количественном отношении компьютерного оснащения учебных аудиторий, степень его соответствия требованиям, предъявляемым к компьютерам для систем ЭО и ДТ; пропускная способность каналов передачи данных); качество технологий обучения (показатели, например, число срывов занятий, стабильность расписания, методики и технологии проведения учебных занятий); качество результата обучения (количество обучающихся, не освоивших программу обучения с ЭО и ДТ; количество обучающихся, освоивших ОП на 4 и 5 ; количество успевающих обучающихся (3,4,5 оценки); отсев обучающихся); удовлетворенность (в качестве показателей выступают результаты опроса обучающихся, педагогов и работодателей, отметим, что удовлетворенность должна составлять не менее 85-90\%).

Основными результатами внедрения системы менеджмента качества являются: повышение удовлетворенности потребителей образовательных услуг, привлечение абитуриентов. Система менеджмента качества инструмент эффективного управления образовательными результатами, позволяющий достичь максимального удовлетворения запросов всех групп потребителей образовательных услуг.

Таким образом, повышение качества образования ориентировано на образовательные результаты, а образовательные результаты невозможно достичь без применения инновационных форм обучения, а именно электронных и дистанционных. 


\section{References:}

1. (2014) Federal law "On education in the Russian Federation". ot 21.12.2012

2. (2015) forms of education in modern conditions. Available: http://internika.org/users/vvn2000/works/novik ov-m-formy-obucheniya-v-sovremennykhusloviyakh (Accessed: 30.01.2015).

3. (2015) Institute of higher education as a factor of formation of student's personality: a sociocultural analysis. Available: http://www.adygnet.ru/sites/default/files/netreb ko disser.pdf\#4 (Accessed: 30.01.2015).

4. (2015) the Papers of young scientists "Values and interests of modern society". Available: http://www.mesi.ru/upload/publication_list/201 3/17.pdf\#4 (Accessed: 30.01.2015).

5. (2015) the Provision of e-learning and distance learning technologies in the University. Available:

http://www.esstu.ru/uportal/document/downloa d.htm? documentId=13369 30.01.2015).
6. (2015) the Provision of e-learning using distance technologies. Available: http:/www.kspu.ru/upload/documents/2014/05/ 26/fa459678521634a35f97d5b073824a97/poloz henie-ob-organizatsii-elektronnogoobucheniya-s-primeneniem-distantsionnyih.pdf (Accessed: 30.01.2015).

7. Seleznev NA (2001) the Quality of higher education as an object of systematic studyLecture - presentation. Moscow, 2001.pp.5.

8. Plexi SI (2003) the Quality of higher education. Moscow,2003.pp.342.

9. Subetto AI (1995) a New quality of higher professional education in modern Russia. Conceptual approach. proceedings of the publishing center. Moscow, 1995. pp.75-87

10. Ilinsky IM (2002) Educational revolution. Moscow, 2002. pp.327. 